\title{
Research on Shenzhen's Maker Movement: Motivation and Its Optimization
}

\author{
Xianwei Zhang \\ Intellectual Property Research Institute, Xiamen University, Xiamen 361005, China \\ xanwey@icloud.com
}

Keywords: Makerspace, Investigation, Optimization, Maker Movement.

\begin{abstract}
This paper reveals the status of Shenzhen's maker movement by concluding an empirical investigation of the operational model of Shenzhen's makerspaces. After pointing out the problems found in the investigation, this paper put forward some suggestions to optimize makerspace's operation and culture cultivation.
\end{abstract}

\section{Introduction}

Shenzhen is China's first state-level innovation city, a region which establish innovation-driven development strategy early. Because of the developed IT industry and manufacturing industry, Shenzhen is one of the most famous maker city around the world.

Currently on the market there are different types of makerspace, which have different resource endowments, different services, and different operating modes. The object of this research is to investigate makerspaces based on the properties of the leading institutions, which are led by scientific research institutes, enterprises and civil public institutions.

This paper selects four typical representatives of makerspaces, they are:

a. Maker Institute, CAS

Features: led by scientific research institutes, and its support projects are mostly research institutes supporting research projects, Premier Li Keqiang specifically investigated this place.

b. SEG Maker Center

Features: business-led, for entrepreneurs to provide one-stop service innovation and entrepreneurial ecological platform.

c. Tencent makerspace

Features: well-known Internet business-led, with help from local governments or state-owned enterprises.

d. Chaihuo Maker Space

Features: knowledge-sharing, creative exchanges and collaborative creation-based non-profit organizations, Premier Li Keqiang specifically investigated this place.

\section{Field Investigation}

\subsection{Maker Institute, CAS}

Shenzhen Nanshan District Government and the Chinese Academy of Sciences, Shenzhen Advanced Technology Research Institute jointly established this makerspace. It is a new science and education innovation platform. It is a space providing services such as schools, passenger space, incubators, and research institutions. It provides free assessment of the young people and provide assessment of the venue and equipment; helping them set up a business and a customer cooperation channels. With guidance from enterprises to provide general direction proposition, makers have targeted to make application projects. Its advantage is its resources, for example:

a. Expert. It has a team of experts in the Chinese Academy of Sciences, each instructor assigned two instructors, one is the College of technical experts to help create a solution to technical problems, the other is the enterprise market experts to help start and market business docking. 
b. Stresses the construction business ecosystem. In the upstream education direction. Maker Institute has been in several colleges and universities and universities to discuss the opening of the elective courses and build a passenger space matters. In the downstream business direction. And electric business enterprises to build a business, for the project to provide online sales channels.

\subsection{SEG Maker Center}

SEG Make Cernter is a joint office space located in Shenzhen Huaqiang North SEG Building. The main advantage of the center is directly located in Huaqiang North, which have regional electronic products store upstream and downstream resources.

a. On the settled selection, maker center and business long-term direct docking. Products are likely to be recognized by the market, and its service team can make prospective judgments, so its entry to the project to small intelligent hardware-based.

b. In product sales, its maker culture to create a platform product marketing and sales at the nation's largest online and offline in the physical stores in the country, open channels maker culture $\mathrm{O} 2 \mathrm{O}$ of products on sale. Crew can directly dock a market, so that consumers experience the scene of the product, to improve market awareness, consumers online and offline can be completed to buy behavior.

c. On prototyping, maker center in the bottom of the country's largest electronic market, from chips, diodes, transistors, sensors, resistors, capacitors, and even various fixture, drill, screw plug, hardware, tools, equipment, apparatus, Instruments, all customers need to find all the raw materials can be found here.

\subsection{Tencent makerspace}

Tencent makerspace is the extenstion of Tencent open platform. Tencent has a dedicated team responsible for docking the various areas of the makerspaces construction work. Tencent outputs its brand and there are a variety of related resources provided by Tencent. Resources can be divided into online resources and offline resources investment in two areas. Online resources are mainly traffic acceleration, customer support and technical guidance; offline resources, including some training, counseling, competition and marketing needs on the promotion of access to resources and so on.

The main advantage of this maker space is

a. Relying on Tencent's brand to attract high-quality projects and investors;

b. Based on the industrial platform Tencent import traffic, users, testing and marketing resources;

c. The local government to build local governments in hardware facilities, reduction of subsidies, were supported on the tax return;

d. Operators franchise model, the operators have their own resources docking venture project requirements.

\subsection{Chaihuo Maker Space}

Chaihuo Maker Space is a non-profit public service space, the implementation of membership mechanism, only due to daily operation and maintenance to members receive a small fee. The Chaihuo space will bring the education into the primary and secondary schools, provide tutorials, teacher training and other solutions, integration of the necessary equipment, teaching materials, tools output to the school. It achieved the following results in just a few years after its establishing:

a. In 47 primary and secondary schools nationwide to build the campus maker culture space, summarizing formed a "primary and secondary schools' maker culture space construction standards" and "primary and secondary school maker culture curriculum teaching and practice of building" ;

b. To promote the country in the country has established more than 100 local maker culture education demonstration sites, mainly in the provinces for the maker culture education.

\section{Problems Found}

From 2015 to 2016, Shenzhen maker space soared from four to more than 200. Innovation takes time to accumulate, business is more difficult, a total of short space within a short period of time, brought some worthy of vigilance.

a. Over-reliance on subsidies 
Under policy guidance, such as financial assistance, direct incentives, tax breaks, subsidies, rent relief or buildings under the incentive, business maker space has become a new form of business or profit-driven, many in order to obtain subsidies from the preferential policy The Compared with the traditional government-led professional technology business incubator, accelerator, the quality of service has declined, becoming "empty shelf", "grocery store".

b. The lack of profit model

On the one hand, due to the short development time, most of the public profit model has not been established, still inherited the traditional technology business incubator to provide space, the collection of rent model; the other hand, many real estate business to join the makerspaces operations, According to real estate ideas to rent space. From the point of view of profitability, rents remain the main source of income, followed by the cost of providing office services and the potential value of future properties.

c. The creation of culture has not yet formed

In foreign countries, is the first growth of the ecological and cultural conditions, and then create their customers and then create a guest space, the last is the mobilization and preparation of the factory production. But the current domestic order is inverted, the first policy introduced, and then there is a makerspaces, and finally to find where the start. In addition to a small number of outstanding public creative space, such as the Branch in a guest college, a passenger in the public record of the occupancy rate is not high Excessive public a thinking type of real estate space, and similar firewood maker culture space or Branch maker culture institute such a focus on the promotion maker culture culture, the maker culture cultivate too little public a number of space operations as a long-term career.

\section{Policy Suggestions}

a. Cultivate a culture of maker and creation

The birth of the cultural atmosphere of commitment to popularization of the fundamental role of popular culture. Foreign maker culture is more than interested to learn, share-driven, maker culture of the English maker does not smack of entrepreneurship. The popularization of the culture is a longterm systematic project, and there are still a series of problems in the development and popularization. For example, the group is still relatively small minority groups, creating enthusiasm is not enough, has not yet formed the hands of everyone to create the situation; committed to cultivate "foster culture" of the public platform is not enough; on the definition and understanding of the culture is narrow Even extreme and so on.

In order to create a culture and atmosphere, and to cultivate the sharing of ecology, government should pay attention to the establishment of primary and secondary schools to build a community, the establishment of student practice room, students held a festival, for the creation and creation of primary and secondary students to provide a full range of services. The Pioneer Toolkit is required to be distributed by the Government and developed by the Education Authorities to develop a dedicated operating room management practice, including safety instructions and opening hours.

b. Improve the makerspaces evaluation index system

For the public record of the assessment of a clear identification of indicators of the evaluation system. For example, in line with the national or local development strategy of the new technology, the new format of the makerspaces should be highly praised.

c. Preferential policy guidance

Will be limited resources in the growth potential of the makerspaces, the focus of subsidies and support. For example, to encourage industrial clusters and enterprises to create cooperation, interaction and innovation, enhance the competitiveness of industrial clusters. For example, to support a makerspace like Shenzhen Chaihuo space to cultivate a customer culture and ecological basis of maker's sharing community.

d. Attach importance to the development of non-profit foundation fund

Foster the development of non-profit maker culture fund, grow maker culture service system body, to solve the maker culture movement all stages of development issues facing the lack of service, providing all-round support for the development of the maker culture "shared ecological community." 
In this field, Britain is typical. The basic characteristics of the development of the UK's founding is the Foundation's co-ordination and the strong support of government agencies, non-governmental organizations and businesses. For example, the British maker culture space Fund is a non-profit organization founded in January 2009, which was established to promote the establishment of new British maker culture space and the development of existing space maker culture, as of January 2015 the institution it has provided services to more than 50 maker culture space. Another example is the National Science and Technology Endowment for the Arts (NESTA) has worked with Nominet Trust and Mozilla, Autodesk and other companies, groups of young people to participate in the expansion of digital production by supporting 14 organizations. These organizations received a total of 52 million pounds, each up to 50,000 pounds of financial support and a lot of support in addition to financial aid.

e. To promote cooperation between enterprises and the makerspaces

To promote innovation and innovation space, to encourage space and many traditional enterprises within the R \& D center to carry out cooperation to build, for enterprise R \& D funding and project support to jointly promote the transformation of Internet enterprises to cultivate around the large enterprise chain of Internet business innovation Ecological circle, to promote the upgrading of local industries and improve quality and efficiency.

\section{References}

[1]. Barton, ANGELA CALABRESE, E. D. N. A. Tan, and Day Greenberg. "The makerspace movement: Sites of possibilities for equitable opportunities to engage underrepresented youth in STEM." Teachers College Record (2016).

[2]. Banks-Hunt, Joan M., et al. "K-12 STEM Education: Bringing the engineering maker space, student-centered learning, curriculum, and teacher training to middle schools." Frontiers in Education Conference (FIE), 2016 IEEE. IEEE, 2016.

[3]. Blackley, Susan, et al. "Makerspace and Reflective Practice: Advancing Pre-service Teachers in STEM Education." Australian Journal of Teacher Education 42.3 (2017): 2.

[4]. Hatch, Mark. The maker movement manifesto: rules for innovation in the new world of crafters, hackers, and tinkerers. McGraw Hill Professional, 2013.

[5]. Dougherty, Dale. "The maker movement." innovations 7.3 (2012): 11-14 